Int. J. Electrochem. Sci., 15 (2020) 2685 - 2699

\title{
Investigation of Adsorption and Inhibitive Effect of Expired Helicure Drug on Mild Steel Corrosion in Hydrochloric Acid Solution
}

\author{
Samar.Y. Al-Nami \\ Chemistry Department, Science College for Girls, King Khalid University, Abha, KSA \\ E-mail: $\underline{\text { salnamee@kku.edu.sa }}$
}

doi: $10.20964 / 2020.03 .34$

Received: 7 November 2019 / Accepted: 22 December 2019 / Published: 10 February 2020

\begin{abstract}
The inhibiting impact of expired Helicure drug (EHD) on the dissolution of mild steel (MS) in $1 \mathrm{M} \mathrm{HCl}$ was evaluated using weight loss (WL) and electrochemical methods. The outcome data displayed that this drug was adsorbed physically on MS surface following Langmuir isotherm. Some thermodynamic factors computed and discussed. The obtained data designated that the protection efficiency (PE) improved by raising the concentrations of the drug and lowered by raising the temperature of the medium. The maximum protection efficiency $85.8 \%$ was detected in the existence of $300 \mathrm{ppm}$ EHD (in case of polarization). The analysis of MS surface are performed by utilizing scanning electron microscope (SEM), Fourier transform Infrared spectroscopy (FTIR) and atomic force microscopy (AFM) tests. All obtained results from different techniques are almost similar.
\end{abstract}

Keywords: Acid corrosion, Mild steel, Expired Helicure drug, SEM, AFM, FTIR

\section{$\underline{\text { FULL TEXT }}$}

(C) 2020 The Authors. Published by ESG (www.electrochemsci.org). This article is an open access article distributed under the terms and conditions of the Creative Commons Attribution license (http://creativecommons.org/licenses/by/4.0/). 